CuPAUAM 23, 1996, pp. 87-113

\title{
PROYECTO DE COLABORACION HISPANO-ALEMÁN EN TORNO A LA INTRODUCCIÓN DE LA NEOLITIZACIÓN EN LAS TIERRAS DEL INTERIOR PENINSULAR: PLANTEAMIENTO Y PRIMEROS RESULTADOS
}

\author{
MANuel A. Rojo GuerRA \\ Profesor Titular de Prehistoria. Universidad de Valladolid \\ Michael KunST \\ Instituto Arqueológico Alemán de Madrid
}

\section{Resumen}

En el presente trabajo se ofrecen los primeros resultados del proyecto de investigación hispano-alemán sobre la introducción de la agricultura en las tierras del interior peninsular. Tras dos años de trabajo de campo conjunto damos a conocer las excavaciones llevadas a cabo en un interesante complejo arqueológico conocido por La Peña de la Abuela/La Lámpara. En él se documenta, por primera vez en la Península Ibérica, una sucesión diacrónica de distintas formas de enterramiento entre los primeros grupos humanos que introdujeron la economía de producción en el Valle de Ambrona, Soria. Si en fechas que el C14 sitúa en torno al final del VI ${ }^{\circ}$ milenio Cal B.C. en La Lámpara se enterraba a los difuntos en fosas excavadas en el suelo, algo más de un milenio después (inicios del rVª Cal. B.C.), sobre el mismo enclave se construyó una tumba monumental (La Peña de la Abuela) cuyo significado se contempla desde la perspectiva de cambios endógenos en la subsistencia, población y ocupación del espacio.

\begin{abstract}
This paper shows the first results of the Spanish-German research work relating to the introduction of the practice of farming in the innerlands of the Iberian Peninsula. After two years of doing fieldwork together, we release the archaeological excavations that we have carried out in a very interesting archaeological site, which is known by "La Peña de la Abuela/La Lámpara". In this site we discovered, for the first time in the Iberian Peninsula, a diachronic succession of different forms of burials among the first human groups who introduced the economy of production in the Valley of Ambrona, Soria. In "La Lámpara" deceased persons were buried in graves that had been dug out in the ground about the end of the VI millennium Cal. B.C. according to C14, but on the same place a monumental tomb was built (La Peña de la Abuela), whose meaning is expalined under the the perspective of internal changes related to subsistence, population and occupation of living space.
\end{abstract}


El proyecto de investigación prehistórica que se inició con la excavación del túmulo funerario de "La Peña de la Abuela" (ROJo GuERra, 1994; Rojo Guerra et alii, 1995) se ha convertido merced a la dinámica propia del yacimiento en un amplio trabajo interdisciplinar que trata de llenar uno de los vacíos más espectaculares de la prehistoria meseteña cual es el conocimiento de la incidencia y desarrollo del proceso neolitizador y la relación entre las estructuras funerarias de este momento (de sobra conocidas y estudiadas) con los correspondientes asentamientos domésticos.

Gracias a los trabajos realizados en los últimos dos años bajo los auspicios de la Junta de Castilla y León, el Valle de Ambrona se ha convertido en un espacio geográfico privilegiado para analizar estos aspectos debido al importante número de yacimientos funerarios y domésticos hallados en una zona relativamente restringida.

La inclusión dentro del equipo investigador del Dr. Michael Kunst del Instituto Arqueológico Alemán de Madrid, ha llevado consigo una intensificación en la investigación a la vez que se ha dado un nuevo respaldo institucional y económico al proyecto, hasta ahora tutelado por el Departamento de Prehistoria de la Universidad de Valladolid. Una faceta de esta intensificación -otras serían los estudios sedimentológicos, palinológicos, radiocarbónicos, paleontológicos... etc.- ha sido la realización de una serie de prospecciones geofísicas (llevadas a cabo por el Prof. Helmut Becker del Bayerisches Landesamt de Munich) en distintos yacimientos del valle, especialmente en el entorno de algunas de las tumbas monumentales, descubriendo que éstas -especialmente la tumba denominada "Peña de la Abuela"- se sitúan en una zona marginal de un asentamiento neolítico doméstico, pero formando parte del mismo.

Una vez que se ha constatado este hecho y la existencia (como más adelante describiremos) de una intensa ocupación del valle en época calcolítica, se nos abre la posibilidad de documentar, en un espacio restringido, cómo fue el proceso de neolitización de las tierras del interior, su desarrollo y de conocer los mecanismos internos que operaron en estas poblaciones en su evolución hacia formas de organización social y económica más complejas. En última instancia se pretende situar la incidencia de esta fase de la Prehistoria en nuestro ámbito geográfico, la Meseta Norte, en el lugar que le corresponde dentro de los estudios sobre Neolítico peninsular, eliminando definitivamente el tópico de marginalidad que la otorgaba una insuficiente investigación hasta la década de los noventa.

Justo es reconocer que a partir de este momento y a raíz de trabajos emanados del Departamento de Prehistoria de la Universidad de Valladolid se ha ido llenando de contenido y significado la expresión NEOLÍTICO INTERIOR con la que Fernández-Posse (1980) definió a esta fase de la prehistoria meseteña. Contenido porque engloba un nutrido conjunto de estaciones en cueva y al aire libre que ocupan de forma bastante generalizada todas las tierras del interior a excepción de algunos sectores marginales (Iglesias, Rojo Y Álvarfz, 1995:722). Significado porque se han ido publicando toda una serie de trabajos (ZAPATERO, 1991; Delibes y Zapatero, 1995 a y b; Palomino y Rojo, e.p.) que le sitúan por primera vez en el tiempo aportando dataciones radiocarbónicas precisas y estableciendo una relación secuencial clara con otras manifestaciones arqueológicas mejor conocidas como puedan ser las tumbas monumentales. 
Es preciso, sin embargo, ampliar cuantitativamente el número de yacimientos que ofrezcan una secuencia clara del desarrollo de estas poblaciones en las tierras del interior y, sobre todo, analizar en lo posible los mecanismos de implantación, desarrollo y, por fin, de transformación en entidades socioeconómicas más complejas. Estas pretensiones son las que, en última instancia, subyacen en nuestro proyecto de investigación, al intentar estudiar en profundidad no ya un yacimiento, sino un espacio geográfico en el que tenemos evidencias razonables de poder dar solución a estas cuestiones. Sólo así, con el estudio intensivo de un espacio restringido, creemos encontrarnos en el camino de dar solución a los distintos problemas que tiene planteados la investigación prehistórica en general, y el conocimiento del proceso de neolitización en particular.

La zona objeto de estudio comprende un estrecho valle en el confín meridional de la provincia de Soria que ocupa parte de los términos municipales de seis núcleos de población en clara regresión demográfica; algunos semiabandonados como Conquezuela y La Ventosa del Ducado y otros con un gran contraste estacional (verano/invierno) como Miño de Medina, Ambrona, Torralba del Moral y Fuencaliente de Medina.

El interés y quizás el acierto de elegir este valle como marco geográfico de nuestro proyecto debe entenderse en función del análisis de dos variables; de un lado su situación concreta dentro de las grandes unidades morfoestructurales y en relación con ciertos factores biogeográficos a gran escala (redes higrográficas) y, de otro, las características peculiares del valle a escala local.

a) Situación en relación con grandes unidades morfoestructurales y factores biogeográficos (Hidrología). El valle se sitúa en el sector oriental de la unidad morfoestructural denominada "Entronque del Sistema Central con el Ibérico" (Palá Bastarás, 1988:14), con unas condiciones geológicas y geomorfológicas determinantes muy diferentes de las limítrofes que se concretan en la Fosa de Almazán/Ariza al norte y los Sistemas Ibérico y Central al sureste y suroeste respectivamente (Figura 1).

Es una franja de terreno levantada con alturas entre 1000 y 1300 metros que se puede considerar una unidad de montaña menor y paramera cuyos rasgos principales están definidos por el arrasamiento desigual de la cobertera mesozoica que sirve de enlace entre el Sistema Central y el Ibérico.

Por tanto, desde esta perspectiva nos hallamos ante una situación geográfica privilegiada ya que se apoya en dos sistemas montañosos, lo que condiciona su elevada altitud, pero a la vez, los suaves anticlinales decapitados por la erosión crean depresiones (Bray) y relieves invertidos (valles afluentes del Jalón) que facilitan la comunicación norte/sur y este/oeste.

La vía este/oeste es nítida y conocemos su uso desde tiempos remotos a través del Jalón (recuérdese que la vía romana que unía Caesaraugusta con Emérita Augusta seguía este recorrido y tenía en Occilis -Medinaceli- un hito importante rememorado aún hoy por su magnífico Arco de Triunfo del siglo II de nuestra Era), lo que uniría el Valle del Ebro con las tierras interiores tanto de la Submeseta Norte como la Sur. 


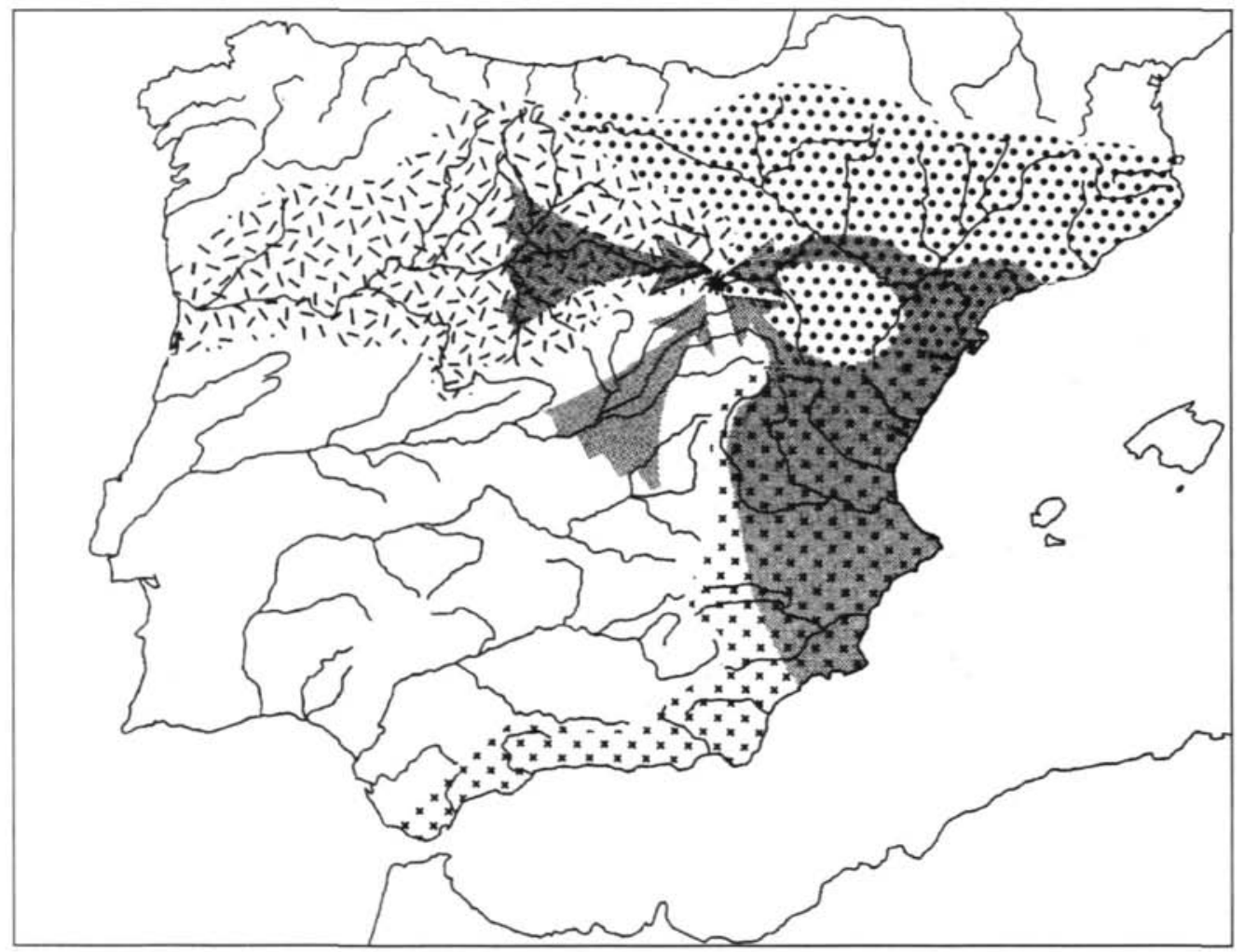

Figura 1. Situación del Valle de Ambrona - en la Península Ibérica ocupando un sector atravesado por vías de comunicación naturales N/S y E/W utilizadas a lo largo de la Historia (tramada punteada) y en la confluencia de varias cuencas hidrográficas ( 1 - 1 Duero. $\because$ Ebro. ." . "Otras cuencas mediterráneas y, en blanco, otras cuencas atlánticas).

La comunicación norte/sur a través de este sector ha sido mucho menos recurrida pero queremos recordar que es el camino más viable, corto y fácil entre el Levante y la Cuenca del Duero y Tajo. En efecto, la franja de tierras elevadas que conforma la paramera de Medinaceli muestra una inflexión hacia el sur, prolongándose a través de las Parameras de Molina hasta las Serranías de Albarracín y Cuenca. Desde la primera, a través del Guadalaviar/Turia, o desde la segunda a través del Cabriel/Júcar se alcanzaría sin mucha dificultad las costas del Levante.

Tampoco está de más recordar que con motivo de la estabilidad que supuso para los reinos cristianos la victoria de las Navas (1212), se creó todo un entramado de comunicaciones norte/sur para facilitar la trashumancia de los rebaños (de ovino fundamentalmente) de los pastizales de verano a los de invierno. Estos grandes desplazamientos se realizaban a través de las cañadas que unían las montanas del norte de León, Palencia, Burgos y Soria con las tierras al sur del Sistema Central. Pues bien, una de las cañadas reales, La Manchega, que 
tenía como punto de origen la serranía soriana, en su ramal oriental cruza perpendicularmente el Valle de Ambrona (coincidiendo en tramos de su recorrido con una antigua vía romana), remonta Sierra Ministra e inflexiona hacia el oeste ligeramente para seguir el valle del Henares a través de Sigüenza y Alcalá. Así, comprobamos cómo también el valle del río Masegar ha sido punto de paso tradicional en las comunicaciones norte/sur a través del Valle del Tajo y nada tendría de extraño que este mismo camino se hubiera utilizado desde el Neolítico a juzgar por la existencia de un importante número de tumbas monumentales en las márgenes de esta cañada que, además, sella el yacimiento también neolítico de La Lampara recientemente excavado y al que más adelante nos referiremos.

Pero hay aún un factor biogeográfico importante que redunda en la consideración de este sector de la provincia de Soria como un área geográfica privilegiada para las comunicaciones en la Prehistoria, se trata de la hidrología. En efecto, el valle se sitúa a caballo de las cuencas fluviales del Duero, Jalón (Ebro) y Tajo -es preciso recordar que el límite meridional del valle está ocupado por Sierra Ministra, un relieve plegado de 1300 metros de altitud máxima en cuyas vertientes norte y sur nacen el Jalón y el Henares respectivamente- y, en concreto dentro del mismo valle (un poljé anticlinal) se encuentra la divisoria de aguas entre el Ebro y Duero (PÉREZ GONZÁlez et alii, 1997:176), lo que hace que se de una indecisa dirección del drenaje en las zonas más arrasadas facilitando la formación de lagunas y suelos con largo encharcamiento que originan biotopos especialmente ricos.

b) Caracteristicas peculiares del Valle (Figura 2). A escala mucho más reducida el valle, caracterizado como un poljé anticlinal que toma el nombre de los tres núcleos de población Conquezuela-Ambrona-Torralba, reproduce fielmente todas las características referidas con anterioridad. En efecto, un poco al norte del núcleo de población de Ambrona se encuentra la divisoria de aguas de las cuencas del Duero y Ebro creándose, en el fondo del valle próximo a la misma, una serie de zonas deprimidas que forman auténticas cuencas endorreicas cuyo drenaje forma una serie de lagunas en torno a las que se desarrollan unos ecosistemas particulares y claramente diferenciados del resto. Se trata de dos lagunas actualmente activas; una en la divisoria de términos entre Miño y Conquezuela que se resiste a desaparecer a pesar de modernas obras de canalización y drenaje hacia el río Bordecorex, y otra, de influencia mucho más reducida, en el término de Miño que se denomina Laguna de La Sima. Existió una laguna más, al norte del núcleo de población de Ambrona, desecada en época reciente, que ocupaba esa "tierra de nadie" entre las dos cuencas fluviales.

Como se apreciará más adelante, en torno a estas reservas de agua se produjo una intensa ocupación antrópica del espacio en época neolítica, manifestada por la presencia de poblados y tumbas monumentales en sus proximidades.

En el extremo noroeste del valle se localiza la cabecera de la Cuenca del Duero ocupada por el río Bordecorex -hoy unido a la laguna de Miño-Conquezuela mediante una vía de drenaje-, que fluye en dirección SO-NE, mientras que justo en el núcleo de Ambrona se encuentra la cabecera del río Masegar/arroyo de La Mentirosa, subsidiario del Jalón que sigue una marcada dirección NO-SE.

En suma, pues, el perfil que presenta el valle en la actualidad es el resultado de la erosión remontante del río Masegar que va capturando esas "tierras de nadie" entre dos cuencas 


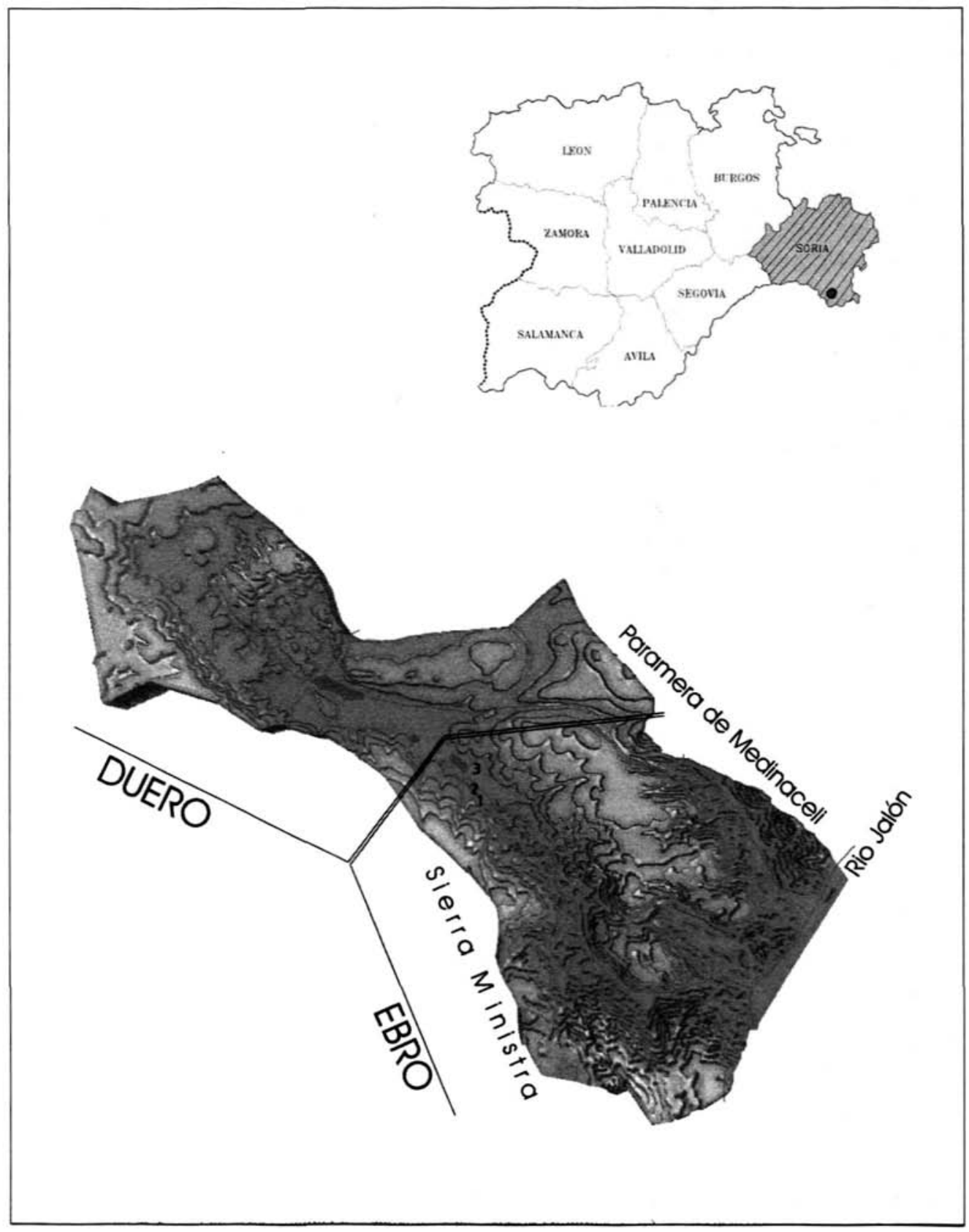

Figura 2. Zona objeto de estudio. Poljé anticlinal Conquezuela-Ambrona-Torralba- con la divisoria de cuencas y situación de los yacimientos analizados en el texto: 1. Peña de la Abuela, 2. La lámpara, 3. La Revilla. 
en dirección al valle del río Bordecorex, hasta establecer la divisoria actual de vertientes al norte del núcleo de población de Ambrona (PÉrez GONZÁlEz et alii, 1997:176). Este hecho está en relación con procesos de erosión remontante general en los que los afluentes del Ebro y diversos ríos mediterráneos, yendo muy rápidos hacia tierras mucho más bajas que las de La Meseta, ofrecen mejor salida a las aguas más interiores del Sistema Ibérico, y con la apertura de gargantas a través de sierras (abundantes pero poco poderosas), conquistan áreas sedimentarias a las cuencas de los ríos atlánticos como pasa con el Jalón en este sector de Soria respecto al Duero o el Júcar respecto al sistema Tajo-Guadiana (PALÁ BASTARÁs, 1988:17).

Otro factor importante a considerar en la configuración del valle es la orografía. El mismo discurre entre las parameras de Medinaceli al norte y Sierra Ministra al sur, originando ambas formaciones notables viseras que se asoman al valle y ocupan lugares estratégicos por su visibilidad dominante en el recorrido del mismo. Estas lenguas de terreno elevadas que penetran en el valle serán ocupadas en un momento de desarrollo de los primitivos pobladores neolíticos. Este cambio que se produce en cuanto al patrón de ocupación del espacio debemos relacionarlo con la transformación de las primitivas sociedades segmentarias en grupos progresivamente más jerarquizados con un control territorial mucho más drástico.

\section{PRIMEROS RESULTADOS DE LA INVESTIGACIÓN}

Las campañas de trabajo de campo efectuadas hasta el presente en el valle han deparado una serie de resultados altamente positivos y sumamente esperanzadores para el futuro del proyecto de investigación. Podríamos resumir los mismos en dos cuestiones principales referidas a la ocupación prehistórica del espacio y a las características de esta ocupación.

a) Ocupación del espacio: Un intenso trabajo de prospección llevado a cabo el último año en todo el Valle de Ambrona por un equipo de cinco personas bajo la dirección de María J. Negredo García ha deparado el hallazgo de una notable concentración de yacimientos que en más de un centenar se distribuyen cronológicamente desde comienzos del Holoceno hasta época histórica (no incluimos en esta apreciación a los yacimientos pleistocenos cuyo estudio aborda otro equipo de investigación bajo la dirección de D. Manuel Santonja, director del Museo de Bellas Artes de Salamanca y D. Alfredo Pérez González, profesor Titular de la Universidad Complutense de Madrid).

La importancia de esta densidad de ocupación queda reflejada en el hecho de que hasta 1996 cuando publicamos un estado de la cuestión sobre el Neolítico en la Submeseta Norte (IGLESIAS, Rojo y ÁlvAREZ, 1996), conocíamos apenas medio centenar de estaciones neolítcas repartidas por todo el interior peninsular, sin embargo, ahora, en el Valle de Ambrona (poco más de $15 \mathrm{~km}$. lineales por 1'5 de anchura) tenemos constancia segura de 15 yacimientos de este período y 19 adscripciones posibles. El hecho tiene el interés añadido de haber documentado estaciones de distinto tipo, tanto domésticas como funerarias (Figura 3). Del mismo modo, se ha constatado una importante continuidad de poblamiento en épocas posteriores como se refleja en la figura 4 en la que aparecen representados los yacimientos calcolíticos y campaniformes hallados en el valle. Actualmente procedemos a un análisis detenido de todas las evidencias con el fin de proponer un modelo de ocupación diacrónica 
del espacio que explique esta sorprendente concentración de yacimientos. En todo caso, un primer análisis de la información obtenida nos marca las siguientes pautas de ocupación del espacio:

1. Presencia de hábitats neolíticos en el fondo del valle o en los rellanos inmediatos a las faldas de la sierra o las laderas de la paramera. La Revilla (19) sería ejemplo del primer caso y La Lámpara (13) y Los Vivarejos/Alto del Pleito (1 y 26) o Cespederas (81), del segundo.

2. Dualidad de ubicación de tumbas monumentales. Mientras que La Peña de la Abuela (17) o el megalito de La Sima (58) ocupan zonas bajas, el túmulo de la Atalayuela (20), Rancho de las Losas (18) o el desaparecido de La Alberca (69) se sitúan en zonas culminantes que dominan el valle.

3. Repliegue de los asentamientos a zonas elevadas y fácilmente defendibles en un momento más evolucionado en el que ya se conoce el retoque plano, con la particularidad añadida de la adicción a los poblados de estructuras defensivas artificiales (murallas). Ejemplos de estas características les documentamos en los presumibles poblados calcolíticos de La Cumbre (35), Navajos (16) y Cerro Santo II (100).

Estas breves pinceladas sobre la adecuación al espacio de los diferentes tipos de yacimientos ponen de manifiesto el interés que suscita un análisis en profundidad de estas cuestiones y una contrastación diacrónica de la evolución del comportamiento desde los primeros pobladores que ocuparon el valle con economía productora, hasta el surgimiento de sociedades mucho más complejas. Estas cuestiones son el reto de futuro de nuestro proyecto de investigación que se pretenden abordar a través de diversas metodologías y aplicando todo tipo de análisis. Así, están en marcha sendos trabajos de investigación sobre la aplicación de técnicas de análisis espacial siguiendo las orientaciones que marcan los trabajos más actuales sobre la llamada Arqueología del Paisaje; se llevan a cabo prospecciones electromagnéticas en cada enclave que consideramos de interés para tener una idea exacta de la organización del espacio a escala menor y, por último, se lleva un estudiado plan de intervención arqueológica en distintos yacimientos que nos permitan conocer su desarrollo secuencial y cultural.

b) Caracteristicas internas de los yacimientos excavados: las intervenciones arqueológicas hasta el momento se han llevado a cabo sobre tres yacimientos (Figura 4 y Lámina I). De forma resumida exponemos las conclusiones más interesantes obtenidas acerca de cada uno de ellos:

1. Tumba monumental de la Peña de la Abuela: la tumba en sí corresponde a un tipo peculiar y prácticamente único en el occidente europeo. Una tumba en la que el fuego ha jugado un papel esencial en su configuración ya que fue construida para ser quemada. En origen se trataba de una "casa de piedra" dentro de la cual se realizaban las correspondientes deposiciones diacrónicamente. Una vez que se dejó de utilizar, el monumento sufrió una ignición completa -tarea que duró unos dos días como mínimo, de tal forma que la estructura de piedra caliza se descompuso en cal viva que con la acción del agua se convirtió en una costra durísima extendida por encima de los propios enterramientos (Lámina II). Así, éstos quedaron completamente sellados para la posteridad a la vez que se conservó -bien es 


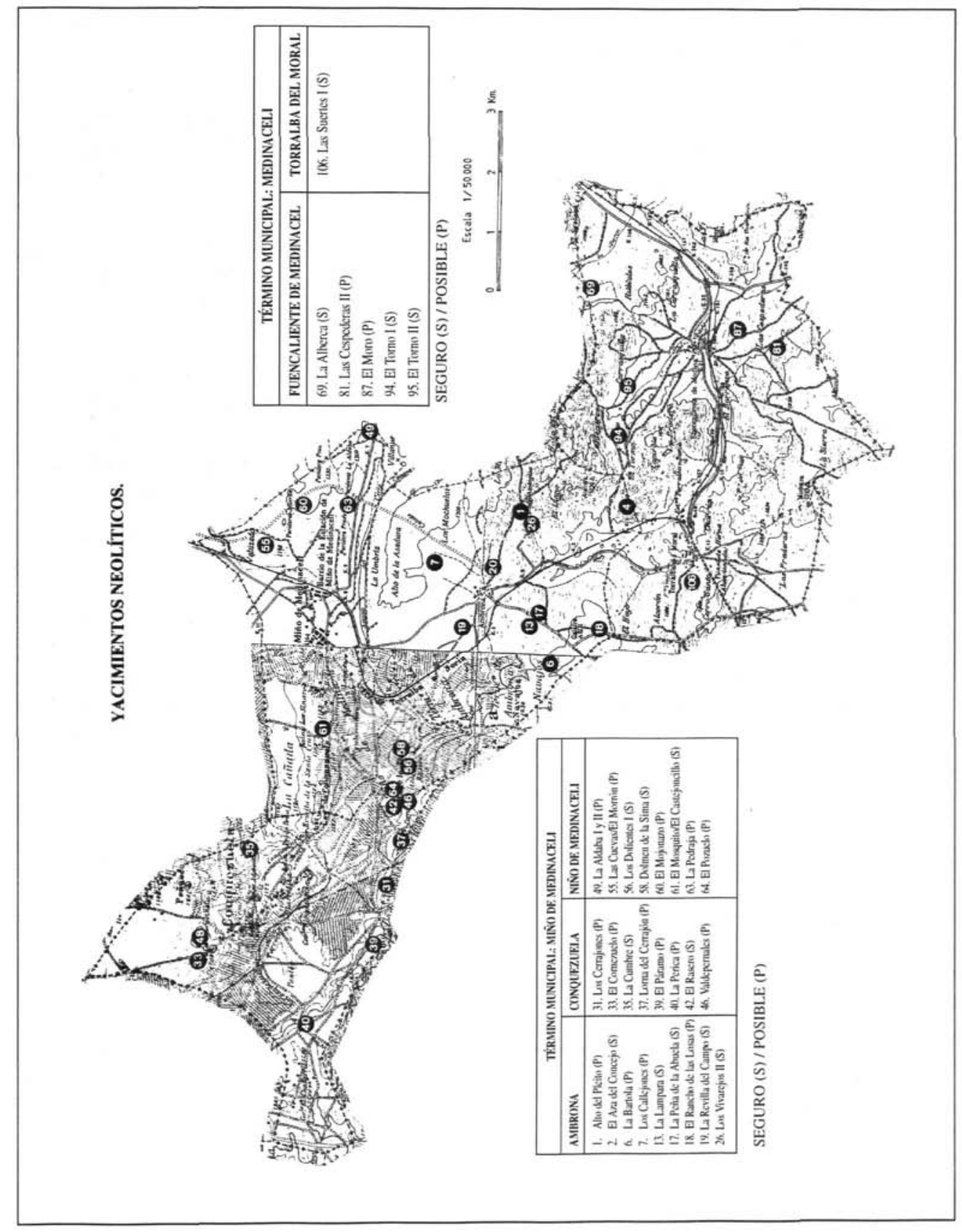

Figura 3. Mapa de distribución de yacimientos neolíticos en el Valle de Ambrona. 


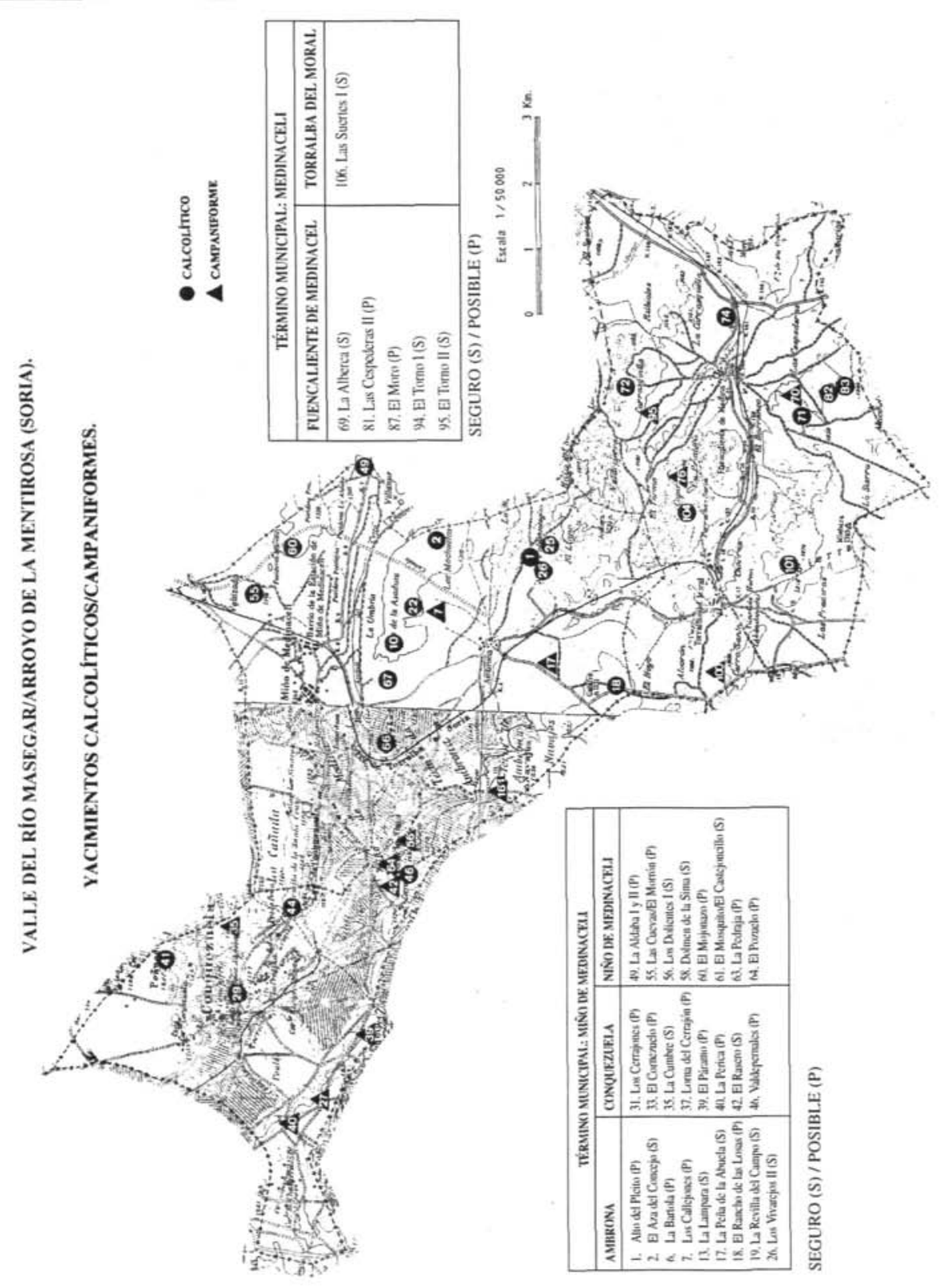

Figura 4. Mapa de distribución de yacimientos calcolíticos y campaniformes en el Valle de Ambrona 


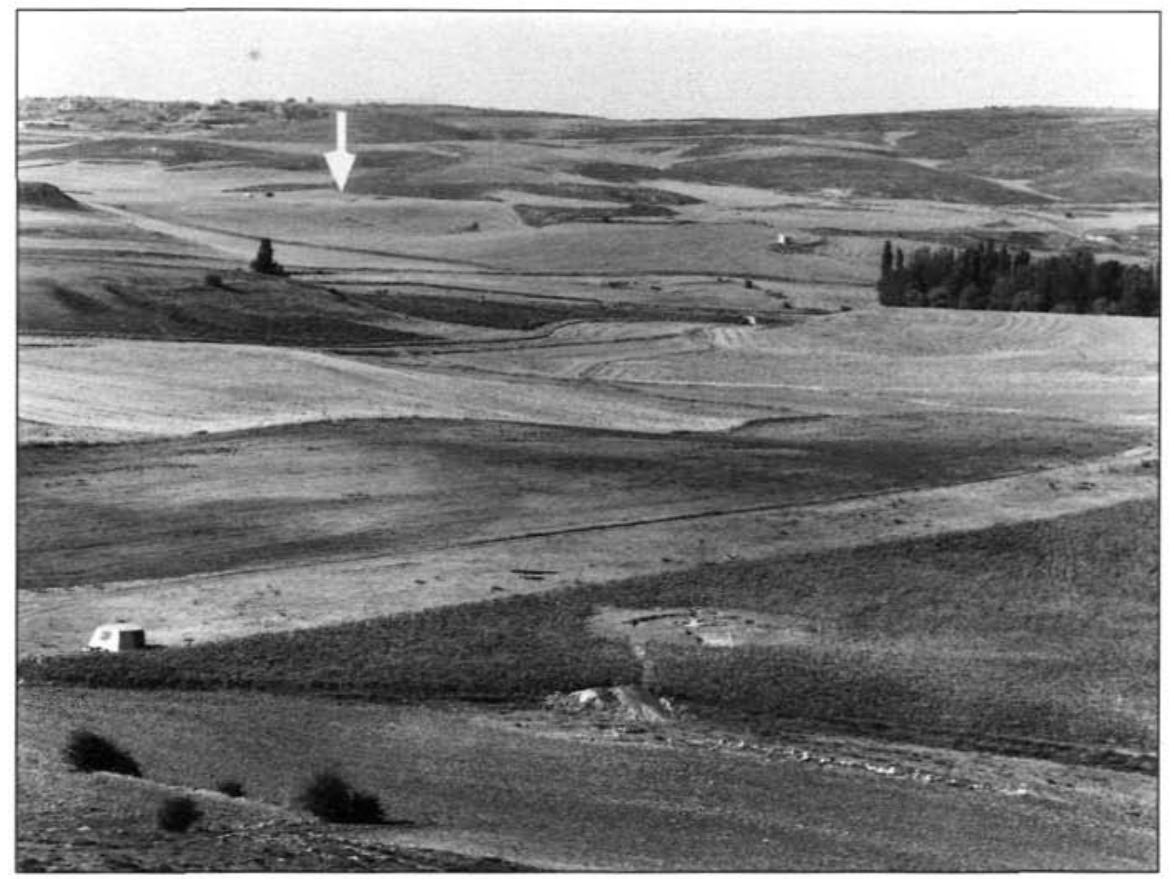

Lámina I. Situación de los yacimientos analizados en el texto. En primer término el complejo La Lámpara / Peña de la Abuela. Al fondo La Revilla del Campo.

cierto que profundamente modificado por el fuego- toda la información necesaria para entender y explicar el proceso de construcción, utilización y abandono de la propia tumba (Rojo et alii, 1995).

Quizás el componente que más se vio afectado fueron los propios enterramientos que se soldaron completamente a toda esta costra calcárea y al nivel inferior debiendo ser retirados en bloques para su posterior excavación minuciosa en el laboratorio. Los mismos fueron transportados a la Universidad de Friburgo donde se ha dispuesto una sala en la que se ha reconstruido el nivel de enterramientos y actualmente se procede con sumo cuidado, a su excavación completa. Las antropólogas de dicha universidad, señoritas Brigitte Lohrke y Babete Wiedmann, dirigidas por el Prof. Kurt Alt, se encargan de esta tarea y del posterior estudio antropológico.

Del proceso de excavación se han extraído una serie de interesantísimos datos para explicar el sentido de la tumba, el proceso de construcción/destrucción seguido, el ritual empleado y la propia composición interna del contenido del recinto sepulcral. De forma sintética relacionaremos los aspectos más destacados:

- Evidencia de segregación espacial dentro de la tumba al disponer de un área que hemos denominado como "zona noble" en la que las inhumaciones aparecen tra- 


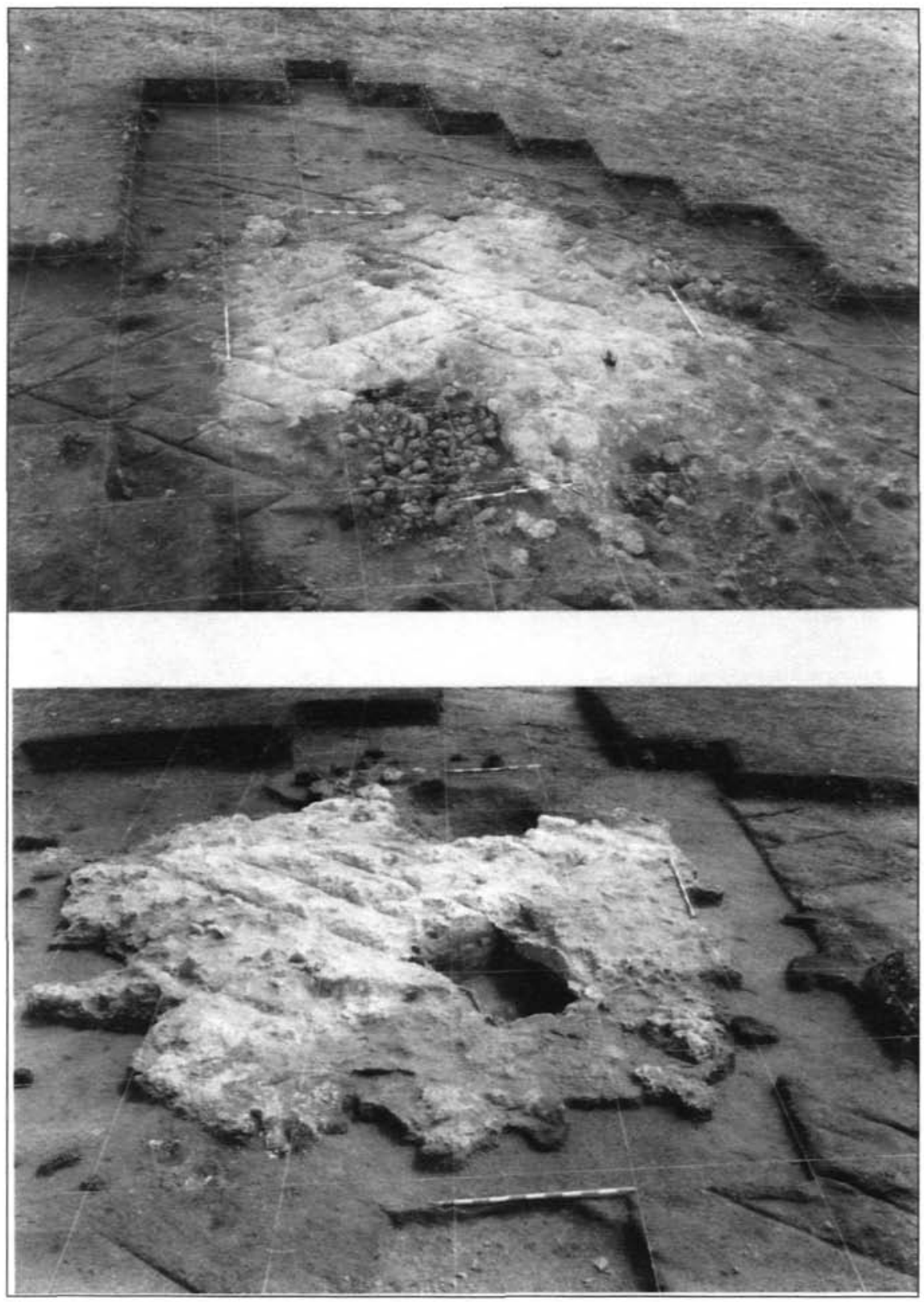

Lämina II: Costra calcárea que cubria todo el nivel de enterramiento. Abajo se observa una de las estructuras (cista) que albergaba un enterramiento segregado del resto. 
tadas individualmente mediante ciertos recursos como son su deposición en cistas o sobre lajas de piedra a modo de expositorios (Lámina III)

- Jerarquización o diferente tratamiento de determinados individuos a los que, además de individualizarles espacialmente, se les deposita envueltos en "sudarios" tejidos con mimbres y juncos y acompañados de ramos de plantas que están en proceso de análisis (Lámina IV y V).

- Tumba de uso diacrónico. El descubrimiento de ciertas remodelaciones y reacondicionamientos del espacio sepulcral nos sirve de prueba definitiva para certificar el carácter de panteón de uso diacrónico de estas tumbas monumentales

- Presencia también de un rico ajuar compuesto por láminas de silex, microlitos y espátulas óseas de forma irregular por todo el recinto sepulcral, siendo más abundantes en el sector de enterramientos individualizados.

En suma, pues, creemos estar ante una tumba única y excepcional que abre un universo de nuevas interpretaciones acerca del mundo simbólico de las poblaciones neolíticas del interior peninsular. Además el hecho de encontrarse inmersa en un yacimiento arqueológico de mayor entidad, con otro tipo de estructuras funerarias y domésticas introduce nuevos parámetros explicativos desde el punto de vista secuencial.

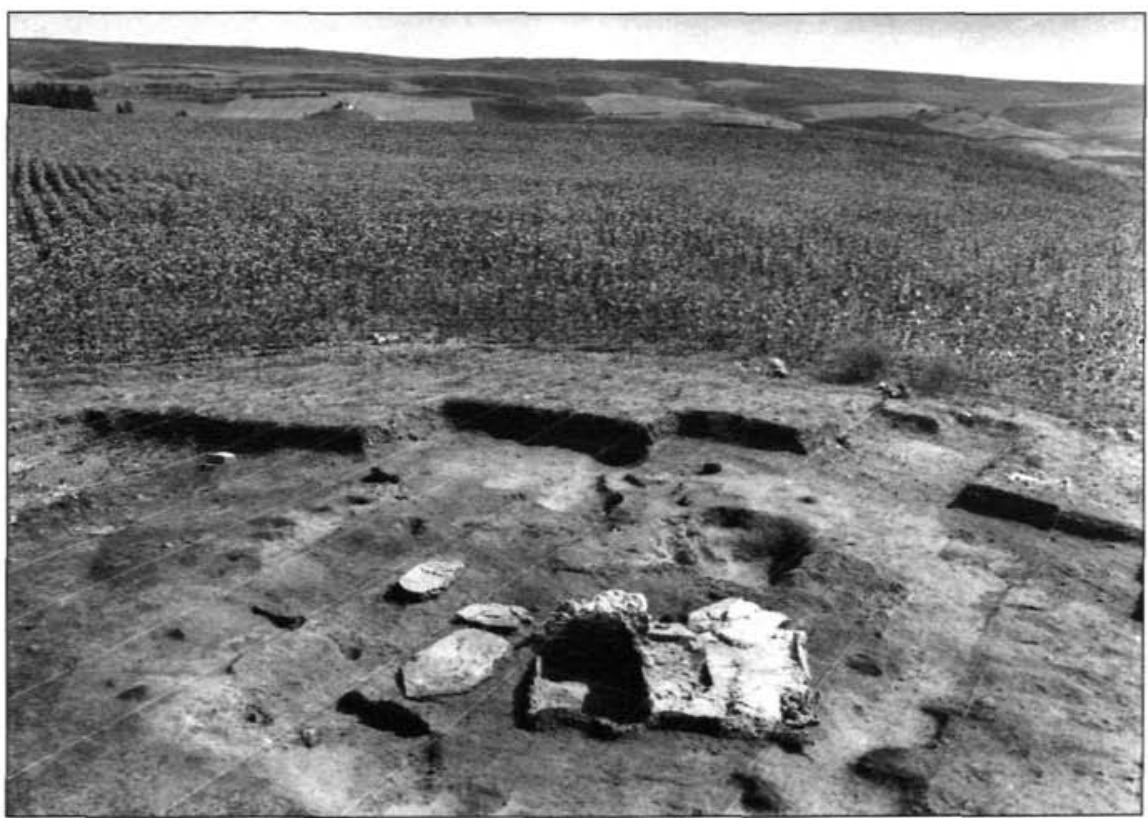

Lámina III. "Área Noble" de la tumba en la que se definen recursos (Cistas, lajas de piedra) de tratamiento individualizado de determinados difuntos. 


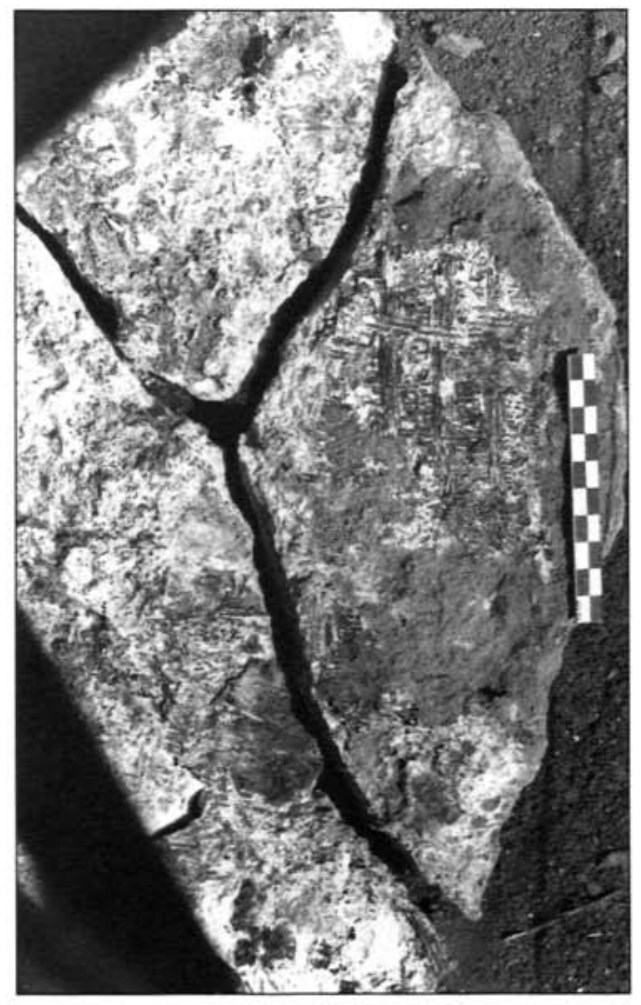

Lamina IV. Restos de un tejido vegetal bajo una laja de caliza.

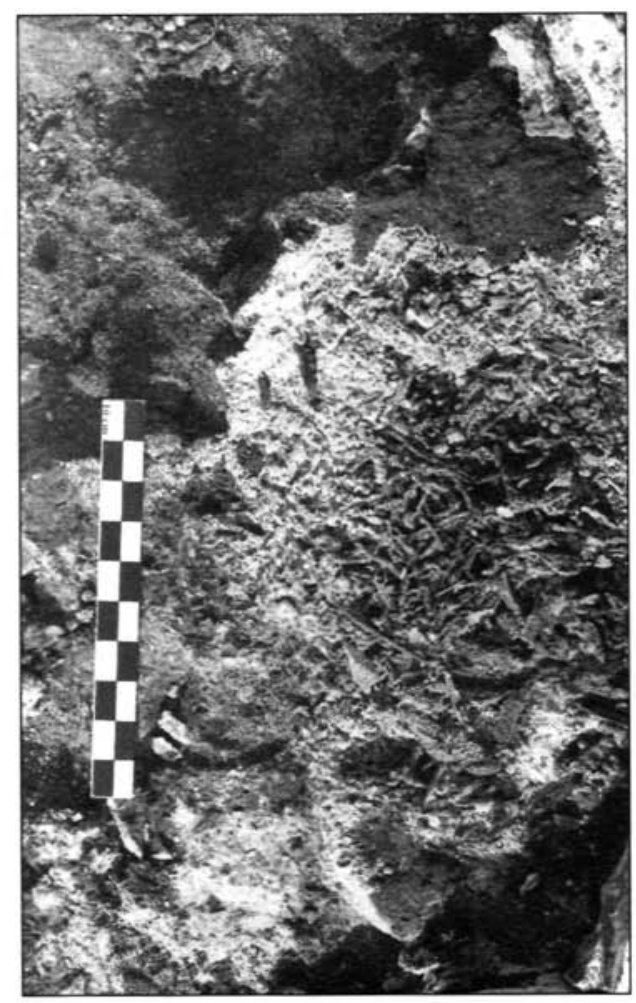

Lamina $\boldsymbol{V}$. Restos de plantas depositadas quizás como ofrendas al difunto.

2. La Lampara: Identificamos con este nombre al yacimiento arqueológico que se ubica en los alrededores de la tumba de La Peña de la Abuela. En prospecciones realizadas durante 1995 y 1996 en torno a la tumba habíamos recogido un nutrido conjunto de materiales arqueológicos (fundamentalmente líticos) que nos hacían pensar en la existencia de un asentamiento de cierta entidad. Esta circunstancia, unida al hecho de apreciar un nivel arqueológico por debajo de la tumba monumental, hizo que encargásemos al Dr. Helmut Becker del Bayerisches Landesamt de Munich, la realización de una prospección electromagnética por todo el asentamiento con la finalidad de confirmar nuestras previsiones y tener la posibilidad de disponer de una planta fiable del subsuelo previa a cualquier intervención arqueológica.

El resultado de este trabajo (Figura 5, arriba) fue la obtención de un mapa de anomalías magnéticas distribuidas de forma un tanto anárquica por una superficie de aproximadamente 1 hectárea de terreno. La excavación de algunas de estas estructuras (de origen diverso, pero siempre en relación con algún tipo de actividad antrópica) nos permitió comprobar 


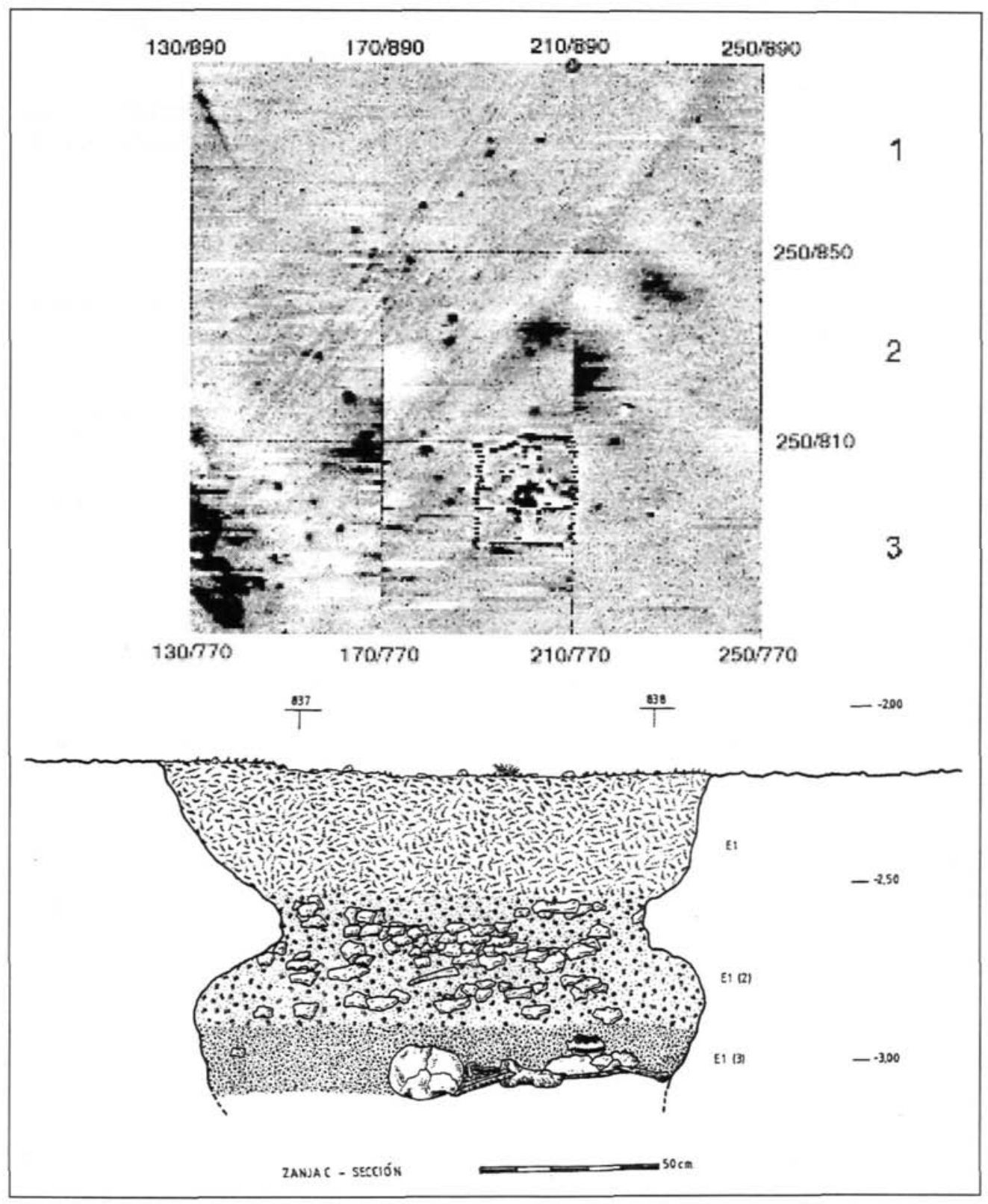

Figura 5. Arriba: Mapa de anomalias magnéticas registradas en el entorno de la tumba monumental de La Peña de la Abuela.

Abajo: Sección de la estructura que contenía la inhumación individual en fosa de la zanja C del yacimiento de La Lámpara. 
que nos encontrábamos ante un asentamiento doméstico caracterizado por la presencia de numerosas estructuras negativas. En efecto, las anomalías magnéticas depararon gran variedad de hoyos, cubetas, silos... que debieron desempeñar papeles distintos en el desarrollo del poblado. Así, mientras en unos casos tenemos una ligera cubeta en forma de casquete esférico de apenas $60 \mathrm{~cm}$. de profundidad a partir del nivel no revuelto por el arado, en otros, podemos afirmar que nos encontramos ante auténticos silos de formas y dimensiones diversas.

Sin embargo, el hallazgo más interesante provino de la excavación de la unidad denominada Zanja C. Allí documentamos una inhumación individual en fosa acompañada de un magnífico ajuar cerámico y lítico. Dado el interés de esta estructura creemos oportuno detenernos, aunque sea someramente, en un análisis más profundo de su dorma y relleno.

Como puede apreciarse en la figura 5, abajo y Lámina VI) nos encontramos ante un hoyo o fosa de tendencia circular -aunque el resultado exacto sea bastante irregular-, que podemos dividir en 3 partes: una boca bastante ancha que medía $150 \mathrm{cms}$. en el borde, cuyas paredes descendian en oblicuo hasta un estrangulamiento a los $40 \mathrm{~cm}$. de profundidad que reducía el diámetro del hoyo a $100 \mathrm{~cm}$. para volver a ensanchar abombándose hasta el fondo de la fosa.

Por tanto, nos encontramos con una estructura negativa de $1 \mathrm{~m}$. de profundidad -aunque la sensación real sobre la excavación era mayor al contar los $40 \mathrm{~cm}$. del nivel superficial-, de tendencia circular, con tres partes definidas: boca, cuello y fondo.

El relleno de la fosa, desde nuestro punto de vista, es parte de una misma realidad y de un mismo proceso de formación. Todo el contenido es muy homogéneo, y si en superficie el hoyo adquiría una coloración marrón más intensa, a medida que profundizamos la única alteración que se produce es la de disminuir en compacidad y aumentar en contenido orgánico. Por ello, la división en niveles -E1, E1 (2) y E1 (3)- se basa más en los componentes del relleno que en una diferenciación estratigráfica clara, ya que estamos convencidos de que todo él es fruto de una misma acción isocrónica de múltiples aportaciones. Ante ello, vamos a describir el relleno por orden inverso a su excavación:

- Nivel E1 (3): Se trata del nivel en el que se depositó el difunto, en el fondo de la fosa. Sin embargo, con anterioridad a la deposición humana se habían arrojado bastantes fragmentos de cerámica, e incluso, algunas grandes fuentes enteras que se hallaban en un deplorable estado de conservación, impidiendo extraer los restos arqueológicos en condiciones idóneas para su reconstrucción, ya que la tierra estaba muy apelmazada, había humedad y la cerámica se desintegraba. No obstante, el material está en proceso de restauración y es posible que podamos disponer en breve de formas y decoraciones.

También se acompañó al difunto de restos de carne de conejo (uno casi entero), y de bóvido (Bos Taurus y Primigenius?), a jugar por la identificación ósea realizada por la. Dra. Corina Liessau y por Dña. Sonsoles Montero.

Todo este nivel, por otra parte, tenía una matriz arcillosa muy fina, que sería la primera tierra que cubriría el difunto, y la coloración oscura la habría adquirido a lo largo del proceso de descomposición de los tejidos blandos del difunto y quizás de los animales. 
- Nivel E1 (2): Este nivel se caracteriza fundamentalmente por la presencia de piedras y de cerámica. Abarca desde los $-2,57 \mathrm{~m}$. a los $-2,90 \mathrm{~m}$. desde el punto $\mathrm{O}-\mathrm{y}$ comienza en el estrangulamiento de la fosa. Se trata, a nuestro entender, del auténtico cierre de la tumba, con piedras, bastante planas las más cercanas al muerto, y el resto, más heterométricas, repartidas de forma anárquica hasta cerrar la parte más angosta de la fosa.

Mezcladas con estas piedras hallamos una gran concentración de cerámica e industria lítica y una buena cantidad de restos óseos de animales entre los que destacamos liebre, ciervo, caballo, toro y un neurocráneo y arranque de cuerno de cabra. Es fácil suponer que, junto a la tarea de colmatado de la tumba y mientras que unos cerraban con piedras y tierra, otros miembros del grupo continuarían depositando ofrendas a modo de cerámicas rotas, huesos de animales y algún útil del difunto como pudieran ser una espátula sobre hueso de animal -aún sin determinar-y un cuerno de ciervo afilado (Figura 6,3).

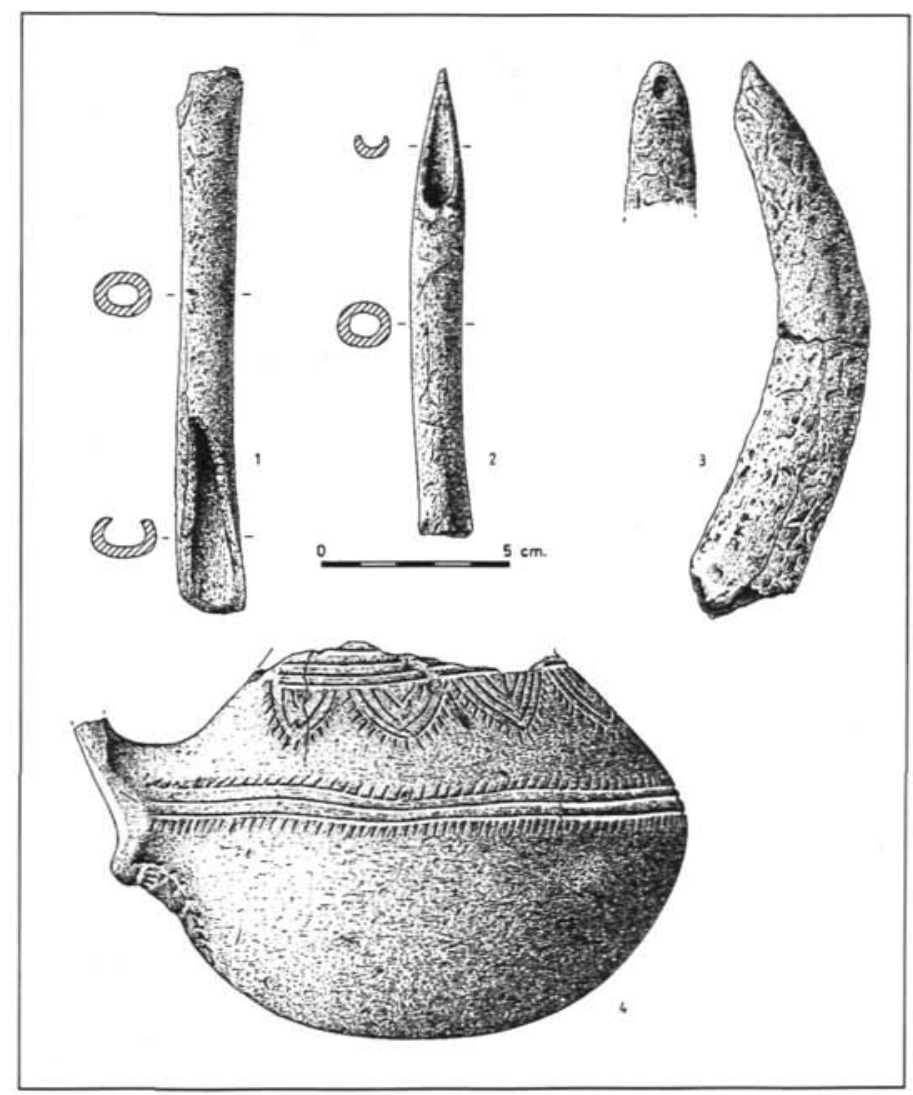

Figura 6. Material óseo y cerámico del ajuar que acompañaba a la inhumación individual de La Lámpara. 
- Nivel E1: Este horizonte del relleno superior de la fosa se caracteriza por su mayor homogeneidad. Se trata de un sedimento marrón oscuro con piedras pequeñas de caliza propias de las tierras del entorno, pero en el que se sigue depositando, no sabemos muy bien si como ofrenda o como simples partes del relleno, vasijas rotas, aunque de forma mucho menos abundante. Es curioso constatar también la presencia de un astrágalo de ciervo (taba) que creemos intencionado, junto a algunos fragmentos óseos de liebre.

De esta forma la tumba quedó sellada, y no creemos que hubiera ningún tipo de estructura en positivo que señalase la misma.

Del ajuar recuperado en la tumba sólo ofrecemos las figuras 6 y 7 en las que presentamos un cuerno de ciervo afilado, un punzón y una espátula y los tres recipientes cerámicos que hasta la actualidad hemos podido reconstruir. Uno de ellos, el número 4 de la figura 6 es la única pieza intacta presente en el relleno habiéndose depositado a los pies del difunto. Sin embargo, a modo indicativo sobre el volumen del ajuar e, indirectamente, sobre la nsideración del difunto/a, podemos cuantificar el total de objetos recuperados como sigue: 365 piezas de las que el 67'4\% (246 piezas) eran cerámicas, el 25'2\% (92 piezas) eran sobre soporte lítico, el 6'5\% sobre tapial y el 0'8\% (3 piezas) sobre soporte óseo.

Destaca por su cuantía el conjunto de piezas cerámicas que presentan los siguientes caracteres generales: técnicamente predominan pastas de color gris oscuro aunque también están representadas las pastas pardas y anaranjadas. Esta coloración implica un predominio de la cocción reductora sobre la oxidante, documentándose también la cocción mixta e irregular. La presencia de desgrasantes es en general abundante, siendo éstos mayoritariamente de tipo mineral (calizos, cuarcíticos y micáceos) y en pequeña medida cerámicos y orgánicos. Las superficies muestran por lo general algún tratamiento, siendo mayoritario el alisado y estando en menor medida presente el acabado brunido y espatulado. También se documenta la utilización de engobes, de tonos pardo, anaranjado y rojo, dispuestos sobre todo en las superficies externas. Se caracterizan tanto por finas capas de pasta muy decantada como por gruesas y toscas capas que llegan a cubrir toda la superficie de la pieza.

Cabe señalar la frágil estructura del material cerámico, que se fragmenta, lamina y desintegra con gran facilidad, esto es debido a su conservación en un ambiente muy húmedo y a la alta presencia de desgrasantes -pasta arenosa-, pero sobre todo indica una temperatura de cocción baja.

Este conjunto está compuesto en su gran mayoría galbos, siendo los bordes, asas y mamelones los únicos elementos formales documentados $(23,5 \%)$. Los primeros son casi siempre de labio redondeado, las asas son tubulares y de cinta, sobre todo verticales, aunque se documentan varias horizontales, en lo que respecta a los mamelones son cónicos y aplastados (orejetas).

En cuanto a la presencia de decoración, se documenta en 41 piezas ( 23 galbos y 18 bordes), lo que supone un $16,6 \%$ del conjunto cerámico. Se localiza en la superficie externa de la pieza y sobre labios, cordones y mamelones, no así en las asas, siempre lisas. Las técnicas utilizadas son la incisión, impresión y aplicación (cordones). Los motivos son líneas paralelas tanto horizontales como verticales y las características acanaladuras, así como los trazos. Tanto técnicas como motivos suelen hallarse combinados. 
En este aspecto decorativo destacan las tres piezas presentadas en las figuras 6 y 7. La primera es un vaso bitroncocónico con una cuidada decoración incisa que afecta al cuello, la panza y bajo el asa. El motivo inciso se complementa con impresiones a modo de flecos que cuelgan de la composición general. Las piezas de la figura 7 tienen formas y motivos decorativos diferentes: la $\mathrm{n}^{2} 1$ presenta una combinación de incisiones paralelas sobre dos bandas de hoyos impresos que se aplican en el tercio superior de un cuenco profundo de fondo hemiesférico con cuatro asas de cinta. La $\mathrm{n}^{2} 2$ responde a una forma de botella con dos asas a partir de las cuales se disponen una serie de bandas impresas formando amplias retículas hacia el borde, y, hacia el fondo cónico, cualgan tres nuevas bandas realizadas también con peine impreso.

3. La Revilla del Campo: Por último, se llevó a cabo otra nueva excavación arqueológica en el yacimiento de habitación de la Revilla del Campo. Al igual que ocurriera en La Lampara, disponíamos de un plano con las anomalías magnéticas elaborado por el Dr. Helmut Becker, por lo que las unidades de excavación (cuatro de diferentes medidas) se dispusieron sobre lo que podrían ser lugares potencialmente fértiles.

De esta manera se excavó una amplia superficie de terreno en la que documentamos algún hoyo que pudo haber servido de silo, y una amplia zanja con relleno de época neolítica pero que dada la escasa perspectiva espacial resulta difícil de explicar desde el punto de vista funcional. La intervención arqueológica más fructífera se produjo en la denominada Cata 2. Allí, junto a dos hoyos en los que se documentaron cerámicas decoradas y algún hacha pulimentada, apareció una estructura de adobes (Lámina VII) en la que, tras la retirada de unas primeras capas de derrumbe, comenzaba a dibujarse la planta de algún tipo de estructura intacta que no podemos precisar con exactitud cuál fuese su funcionalidad.

La dificultad de excavar estructuras de adobe hizo que los trabajos se desarrollasen con lentitud lo que impidió concluir con la excavación de toda la estructura, tarea ésta que se pretende realizar en la campaña que en este yacimiento tenemos planeado para el verano de 1999. Las razones de esta demora en la finalización de la excavación obedece a cuestiones relacionadas con la propiedad y el uso de la tierra en 1998.

\section{CONSIDERACIÓN FINAL: CONTEXTUALIZACIÓN Y POSICIÓN CRONOLÓGICA A LA LUZ DEL C14.}

Hasta aquí hemos pretendido presentar, un tanto precipitadamente, los primeros datos objetivos aportados por los trabajos de campo efectuados en el Valle de Ambrona, Soria. Es nuestra intención ofrecer a continuación una contextualización de los mismos a la luz de las fechas aportadas por el C14 y de los paralelos formales y decorativos de las cerámicas presentadas.

Mientras se confirman con nuevos análisis, disponemos de fechas radiocarbónicas que sitúan los yacimientos en clara sucesión diacrónica. Así, las dataciones actuales, efectuadas en el Laboratorio Leibniz Labor für Altersbestimmung und Isotopenforschung de la ChristianAlbrecht-Universität de Kiel, son los siguientes: 


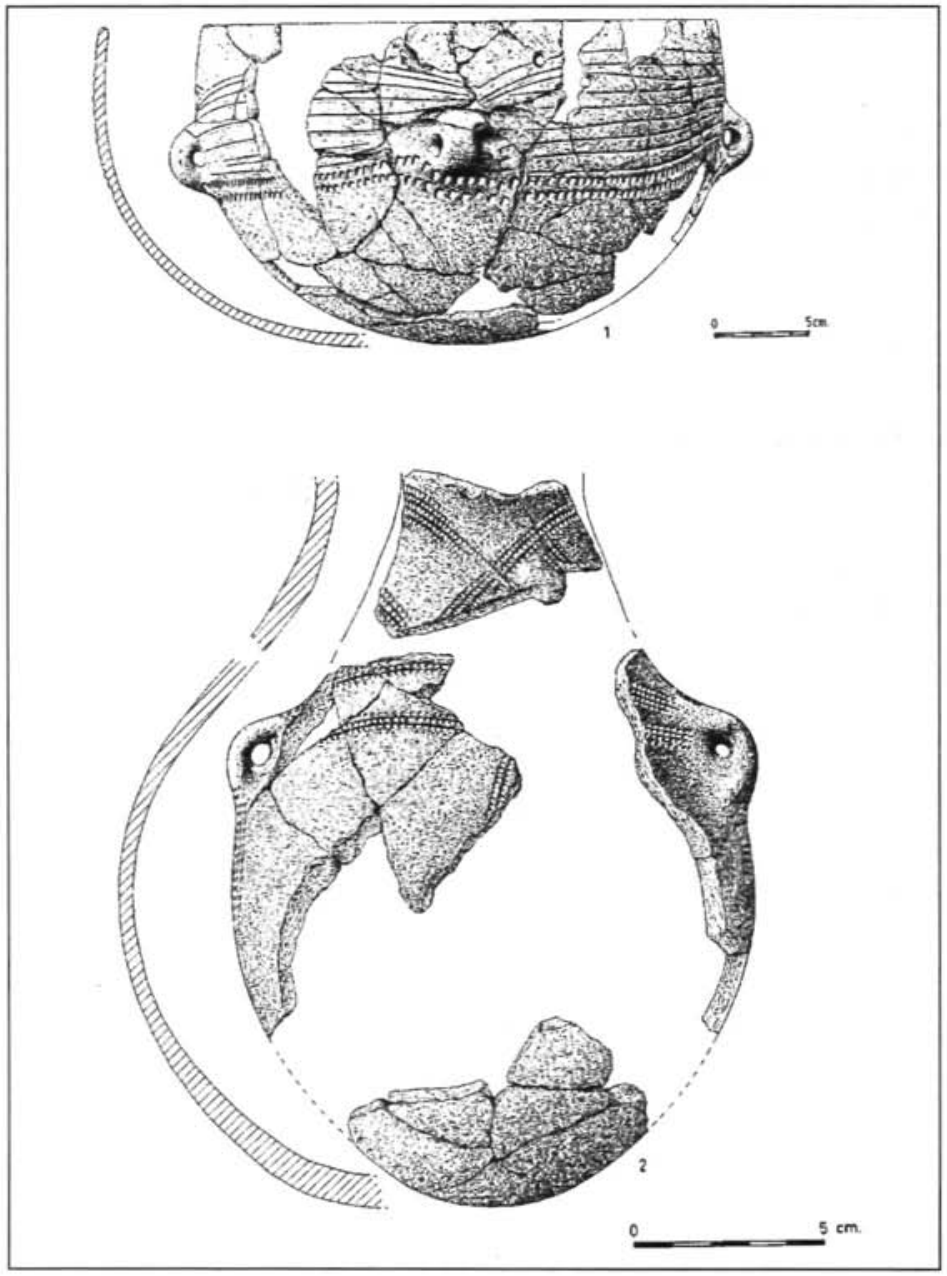

Figura 7. Reconstrucción de recipientes cerámicos que acompanaban como ajuar a la inhumación individual en fosa de La Lampara.

\section{Yacimiento de La Lámpara:}

KIA 4780. La Lámpara 143. Carbón Vegetal. Nivel de enterramiento.

KIA $4780.6390 \pm 60 \mathrm{bp}$.

Calibración. Cal BC. 5420, 5410, 5380, 5330.

$\begin{array}{lll}1 \sigma: \mathrm{Cal} . \mathrm{BC} . & 5431-5356 & 5352-5276 . \\ 2 \sigma: \text { Cal B.C. } & 5439-5256 & 5230-5218 .\end{array}$




\section{Yacimiento de La Peña de la Abuela:}

KIA 4781. Peña de la Abuela. Madera nivel de enterramiento (carbón vegetal)

KIA 4781. $5050 \pm 50 \mathrm{bp}$.

Calibración. Cal BC. 3903, 3881, 3866, 3864, 3800.

$1 \sigma$ : Cal B.C. $\quad 3943-3764$.

$2 \sigma$ : Cal B.C. $3964-3707$.

\section{Yacimiento de La Revilla del Campo:}

KIA 4782. La Revilla del Campo. Carbón vegetal.

KIA 4782. $4750 \pm 80 \mathrm{bp}$.

Calibración. Cal. B.C. 3624, 3596,3536.

$1 \sigma$ : Cal. B.C. 3642-3498 3464-3376.

2 б: Cal. B.C. 3701-3682 3671-3352.

La primera de las fechas ( $6390 \pm 60$ b.p.) nos sitúa La Lámpara en una fecha muy temprana que podemos situar en el último tercio del $\mathrm{VI}^{\circ}$ milenio en fechas calibradas. Este dato envejece en dos siglos las dataciones más antiguas que disponíamos para el Neolítico Interior en el nivel inferior del yacimiento palentino de La Velilla (DELIBES Y ZAPATERO, 1996) a la vez que sitúa la introducción de la economía de producción en la Submeseta Norte en un momento paralelizable con el mismo proceso en el Valle del Ebro.

En efecto, el fenómeno de la neolitización de las tierras del interior peninsular parece, hoy por hoy, el reflejo claro de una corriente de difusión cuyo origen debemos buscarle en el ámbito del Mediterráneo Occidental. La falta de un sustrato epipaleolítico claro hace que no podamos plantear ningún otro modelo de neolitiación como algunos autores parecen defender para determinadas zonas del Bajo Aragón (BARANDIARÁN, 1978; BARANDIARÁN Y CAVA, 1992) e incluso ciertos sectores más al interior donde la ocupación neolítica de algunos enclaves como Peña de las Forcas II (Mazo y Utrilla, 1992) o El Pontet (Mazo y Montes, 1992) se instalan sobre ambientes epipaleolíticos. Mucho menos, todavía, estamos en disposición de plantear tesis autoctonistas del tipo de las defendidas para Cova Fosca (OLARIA, 1988) a pesar del paulatino envejecimiento de las dataciones absolutas que va deparando la intensificación de la investigación en nuestro ámbito geográfico llegando a rivalizar en antigüedad con las estaciones más viejas de las zonas costeras como ha manifestado recientemente Alfonso Alday al presentar en el I Congreso de Historia de Burgos los datos extraídos del Abrigo de Mendandia en el Condado de Treviño, Burgos.

Con todo, creemos que el pretendido camino de difusión -en el que no debemos de excluir como mecanismos de transmisión de ideas y de conocimientos modelos que contemplen procesos de aculturación (BERNABEU, BADAL y AURA, 1993: ZveleBil, 1986)-, alcanzó las tierras del interior peninsular, y en concreto de la Submeseta Norte, a través del Valle del Ebro y su afluente el Jalón. No pretendemos afirmar que la colonización neolítica de este amplio sector geográfico haya tenido una sola vía de acceso (es posible que se puedan contemplar algunas otras justo en el sector suroeste de la Cuenca del Duero), pero sí que cree- 


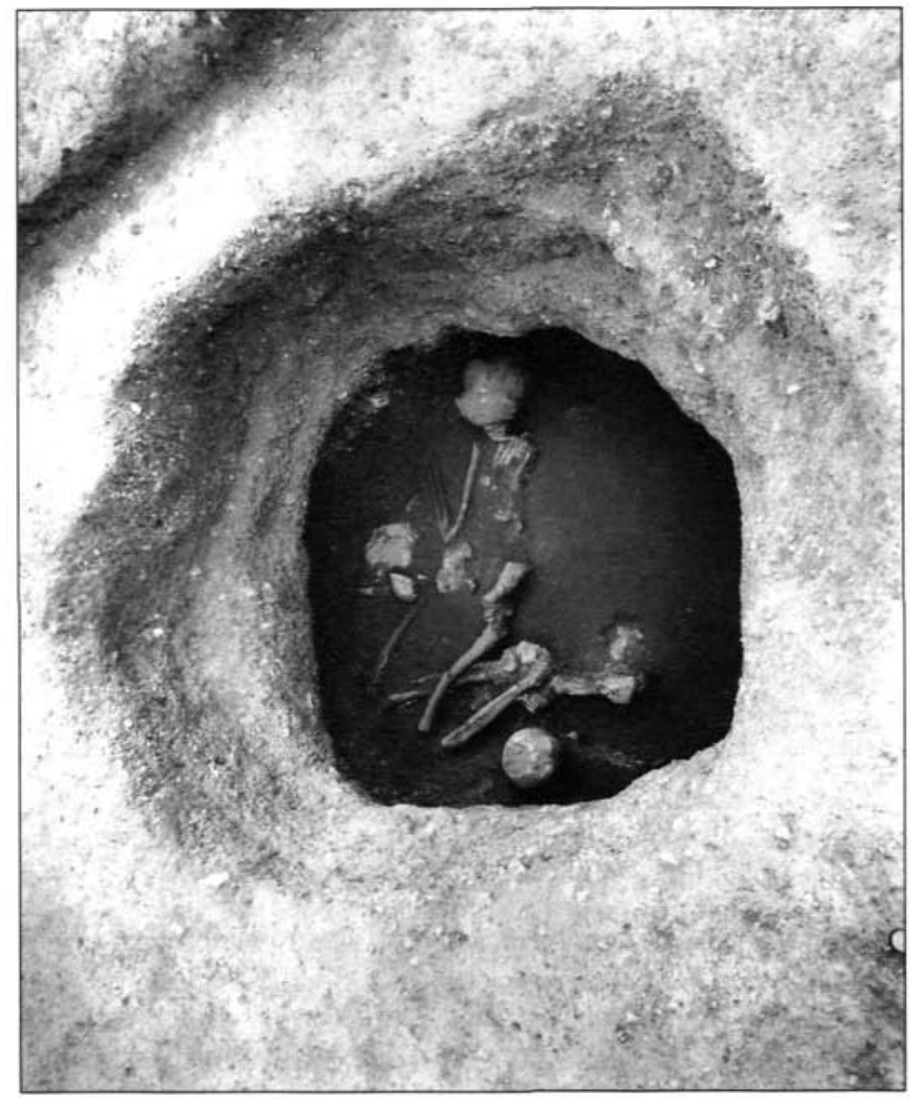

Lámina VI. Vista general de la fosa excavada en la zanja C de la Lámpara con la inhumación individual.

mos estar autorizados, a la luz de los datos expuestos, a considerar la del Valle de Ambrona como una de las más antiguas vías de penetración de las poblaciones neolíticas al interior peninsular.

Existen a lo largo de todo el Valle del Ebro una serie de hitos muy importantes que jalonan este camino desde el Mediterráneo. La fecha absoluta aportada por La Lámpara sitúa el primer Neolítico del Valle en el mismo horizonte cronológico que los yacimientos aragoneses de Chaves, Olvena superior, Forcas II, Costalena (C1 y C2), Pontet (c inferior y superior), Botiquería dels Mors ( 6 y 8 ) y Secans, considerados, todos ellos, en un reciente trabajo de Rodanés y Ramón (1995, cuardro 9) como la primera fase o Neolítico I en la evolución del Neolítico en Aragón.

Pero no sólo desde el punto de vista de la cronología absoluta La Lámpara se relaciona con esta primera fase del neolítico aragonés. En efecto, una vez desacreditada, a nuestro 


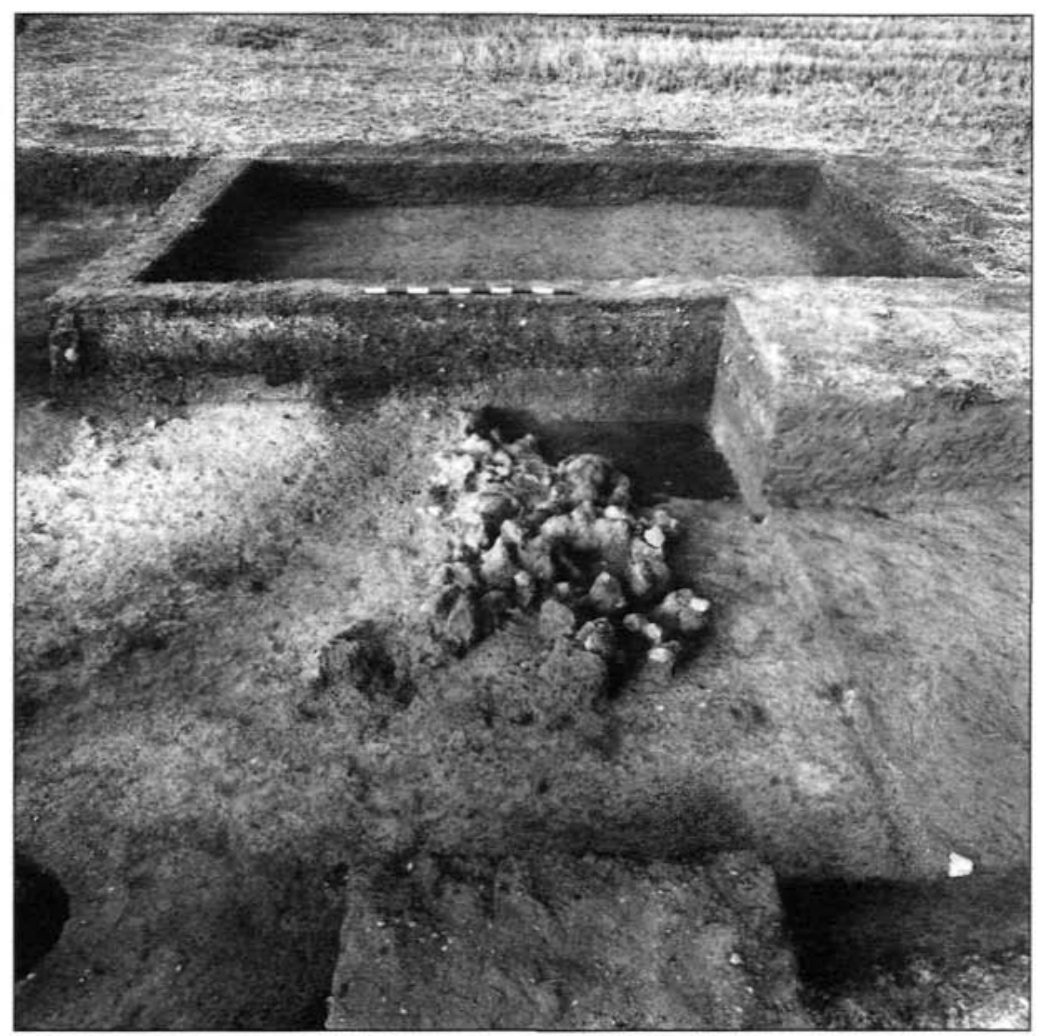

Lämina VII. Derrumbe de adobes en La Revilla del Campo.

entender de forma acertada, la división o secuencia Cardial/Epicardial por los autores anteriormente mencionados, quedaría como sustrato cultural, en lo que a producción cerámica se refiere, un horizonte de motivos impresos e incisos sobre un variado (aunque limitado) soporte formal. Pues bien, estas mismas técnicas decorativas caracterizan el conjunto ornamental que hemos recuperado en la tumba de La Lámpara. Los motivos incisos e impresos que aparecen en las figuras 6 y 7 tienen reflejos evidentes en numerosos yacimientos aragoneses y, especialmente la pieza número 2 de la figura 7 porta una decoración de peine impreso que se podría calificar de epicardial con paralelos claros en Chaves (BALDELLOU, 1983) y que no desentonaría en cualquier contexto de este tipo desde el Mediodía francés hasta el sur peninsular.

En el estado actual de la investigación pocas apreciaciones más podemos realizar sobre el conjunto cerámico exhumado en La Lámpara. Únicamente queremos señalar que, sin 
ninguna duda, se trata de una deposición instantánea que define un momento concreto y, por tanto, se nos escatima la posibilidad de establecer una seriación secuencial de tipos y motivos decorativos. Esta pretensión es uno de los retos a los que se enfrenta nuestro proyecto de investigación en el futuro con la clara intención de conocer la evolución tecno-tipológica de la producción cerámica a lo largo del tiempo en el seno de las primeras poblaciones productoras del Valle de Ambrona.

La segunda de las fechas absolutas presentadas corresponde al nivel de enterramientos de la tumba monumental de La Peña de la Abuela. Según el resultado de la misma ( $3.100 \pm 50$ b.c. ó 3964 Cal B.C. a $2 \sigma$ ) esta singular tumba monumental se construye y utiliza en la misma época que gran parte de los monumentos megalíticos dela Meseta Norte (DeLiBES et alii, 1992; DeliBES Y ROJO GUeRRA, 1997) y, resulta especialmente sincrónica de otra tumba con la que comparte evidentes afinidades como es El Miradero en Villanueva de los Caballeros, Valladolid (Delibes, Alonso y Galván, 1986).

Pero quizás la enseñanza más interesante que se pueda extraer de la datación de este monumento radique en una circunstancia ajena a la propia posición cronológica y que se relaciona con el hecho de situarse la tumba en el mismo espacio que el asentamiento funerario/doméstico de La Lámpara.

Esta sucesión espacio doméstico/espacio funerario, que poco a poco se está haciendo habitual en los trabajos sobre el fenómeno megalítico de la Meseta Norte (DeLIBES Y ZAPATERO, 1996: Palomino y Rojo, 1997), adquiere aquí, en el complejo La Lámpara/Peña de la Abuela, una dimensión especial al documentar por primera vez una diacronía de tipos de enterramientos (individual primero y colectivo después) en el mismo enclave.

Este hecho se nos antoja crucial a la hora de explicar el cambio mental que se produce entre una concepción de la tumba como algo personal, íntimo y oculto, frente a la exhibición monumental y simbólica que supone una construcción pétrea que se convierte, quizás, en la primera huella humana visible y perdurable en un paisaje cada vez más antropizado. No es el objetivo del presente trabajo profundizar en estas cuestiones, sin embargo queremos realizar una reflexión final a este respecto. No podemos estar seguros de que la misma población evolucionase desde una concepción mental a la otra (recuérdese el desfase cronológico de unos mil años entre una y otra), pero creemos que la posible explicación a este hecho radica en una serie de cambios endógenos en la subsistencia, asentamientos y sociedad que conducen a la necesidad de establecer símbolos de propiedad perdurables en el tiempo y visibles en el espacio.

La prosecución de nuestro proyecto de investigación con la identificación y excavación de nuevos asentamientos neolíticos nos capacitará para determinar si estos cambios son reales y si se demuestra un aumento claro de población en el valle en una fase avanzada en la que el Neolítico está ya plenamente consolidado.

Por último, la tercera de las fechas presentadas corresponde al yacimiento de La Revilla del Campo, próximo al enclave de La Lámpara/Peña de la Abuela del que le separa en línea recta una distancia que ronda el kilómetro. Quizás en La Revilla nos hallamos ante uno de estos yacimientos de habitación que testimonien, junto a la proliferación de estructu- 
ras funerarias tumulares (ver figura 3) un claro aumento de población en torno al tránsito del IVa al IIIer milenio b.c. en fechas sin calibrar. La datación obtenida del $2.800 \pm 80$ b.c. ó 3701 Cal B.C. a $2 \sigma$, no podemos, por el momento, ponerla en relación con un conjunto amplio de material arqueológico que completase una secuencia de evolución local por comparación con las estaciones antes mencionadas. No obstante, con la prosecución de las excavaciones en el verano de 1999 estaremos en disposición de completar una primera aproximación a la evolución y desarrollo temporal y tecno-tipológico de las poblaciones neolíticas del valle.

A pesar de las limitaciones que se advierten en esta etapa aún embrionaria de la investigación sobre el Neolítico en el Valle de Ambrona creemos haber ofrecido una serie de datos interesantes que nos permiten establecer la presencia de los primeros pobladores con economía productiva en torno a la segunda mitad del $\mathrm{VI}^{2}$ milenio en fechas calibradas. Estos grupos definirían la primera fase o Neolítico Inicial caracterizada por el enterramiento individual en fosa desde el punto de vista funerario, por un asentamiento doméstico de estructuras negativas desde el punto de vista habitacional y por la impresión e incisión desde el punto de vista técnico en lo referente a la decoración de las producciones cerámicas.

Un Neolítico Pleno, insuficientemente caracterizado por el momento, se desarrollaría en torno a los inicios del $\mathrm{IV}^{2}$ milenio en fechas calibradas y su característica fundamental residiría en el empleo de un ritual funerario colectivo en el interior de tumbas monumentales.

A definir de forma más precisa ambas fases, a completar el desarrollo temporal entre ellas y a establecer los epígonos del Neolítico en el Valle de Ambrona irán dedicados los empeños de nuestro proyecto de investigación en los próximos años.

\section{REFERENCIAS BIBLIOGRÁFICAS}

Baldellou, V. (1983): "La Cueva de Chaves en Bastaras: comentario a los materiales neolíticos". Bolskan, 1, pp. 67-94.

Barandiarán, I.: (1978): "El Abrigo de Botiquería dels Moros, Mazaleón (Teruel). Excavaciones arqueológicas en 1974". Cuadernos de Prehistoria y Arqueología castellonense, 5, pp. 49-138.

Barandiarán, I.; CAVA, A. (1989): La ocupación prebistórica del abrigo de Costalena (Maella, Zaragoza). Col. Arqueología y Paleontología, Serie Arqueología Aragonesa. Monografías n² ${ }^{2}$ Diputación General de Aragón.

Delibes de Castro, G.; Alonso Diez, M.; Galván, R. (1986): "El Miradero: un enterramiento colectivo tardoneolítico de Villanueva de los Caballeros (Valladolid)". Estudios en bomenaje al Dr. Antonio Beltrán, Universidad de Zaragoza.

Delibes, G.; Palomino, A.L.; Rojo Guerra, M.; Zapatero, P. (1992): "Estado actual de la investigación sobre el megalitismo en la Submeseta Norte", Arqueología, 22, GEAP, pp. 9-21. 
Delibes, G.; Rojo Guerra, M. (1997): “C14 y secuencia megalítica en la Lora burgalesa: acotaciones a la problemática de las dataciones absolutas referentes a yacimientos dolménicos", en Rodríguez Casal, A. (ed): O Neolitico atlántico e as orixes do megalitismo, actas do coloquio internacional, pp. 391-414.

Delibes De Castro, G.; Zapatero Magdaleno, P. (1995): "Sobre la implantación del megalitismo en el Valle Medio del Duero: el testimonio de La Velilla. En Osorno (Palencia)". Actas del III Congreso de Historia de Palencia, tomo I. Excma. Diputación provincial, pp. 35-63.

- 1996: "De lugar de habitación a sepulcro monumental: una reflexión sobre la trayectoria del yacimiento neolítico de La Velilla, en Osorno (Palencia)", en Actes del I Congrés del Neolitic a la Península Ibérica. Formació i implantació de les comunitats agrícoles. Rubricatum 1, vol. 1, pp. 337-345.

Ffrnández-Posse, M.D. (1980): "Los materiales de la cueva del Aire de Patones (Madrid)", Noticiario Arqueológico Hispánico, n² 10, pp. 41-64.

Iglestas Martínez, J.C.; Rojo Guerra, M. A.; Álvarez Periañez, V. (1996): "Estado de la cuestión sobre el Neolítico en la Submeseta Norte". Rubricatum 1, Congrés del Neolític a la Península Ibérica, Vol. 2. Gavá-Bellaterra, pp. 721-735.

Mazo, C.; Montes, L. (1992): "La transición epipaleolítico-neolítico antiguo en el abrigo de El Pontet (Maella, Zaragoza)". Aragón/Litoral mediterráneo: intercambios culturales durante la Prebistoria, (Zaragoza, 1990), Zaragoza, pp. 243-254.

Mazo, C.; Utrilla, P. (1994): "La excavación de los Abrigos de Las Forcas (Graus, Huesca) en la campaña de 1992" Arqueología Aragonesa 1992, pp. 31-37.

OlaRIA, C. (1988): COVA FOSCA. Un asentamiento neolítico de cazadores y pastores en la serrania del Alto Maestrazgo, Monografies des Prehistoria i Arqueología castellonenses, $\mathrm{n}^{2} 3$, Castellón de la Plana.

Pala Bastaras, J.M. (DIR) (1988): Análisis del Medio Físico de Soria. Delimitación de unidades y estructura territorial. Junta de Castilla y León, Consejería de Fomento, 117 págs.

Palomino Lázaro, A.; Rojo Guerra, M.A. (1997): "Un nuevo yacimiento neolítico de habitación infratumular: "el Teso del Oro"”, en San Martín de Valderaduey (Zamora). II Congreso de Arqueología Peninsular, Zamora.

Pérez González, A.; Santonja, M.; Gallardo, J.; Aleixandre, T.; Sese, C.; Soto, E.; Mora, R.; Villa, P. (1997): "Los yacimientos pleistocenos de Torralba y Ambrona y sus relaciones con la evolución geomorfológica del Poljé de Conquezuela (Soria)". Geogaceta. Sociedad Geológica de España, n² 21, Mayo, pp. 175-178.

Rodanes, J. Mª.; RAMÓn, N. (1995): "El neolítico antiguo en Aragón: Hábitat y territorio", Zephyrus, XLVIII, pp. 101-128.

Rodanes Vicente, J. M.; Tilo Adrián, M.A.; Ramón Fernández, N. (1986-87): "Excavaciones arqueológicas en el abrigo del Secans (Mazaleón, Teruel). Primera campaña”. Kalathos, 7-8, pp. 25-43. 
ROJO GuerRA, M.A. (1994): "Nuevos monumentos tumulares en la provincia de Soria: reflexiones en torno al megalitismo de la Submeseta Norte", RICUS (Geografía e Historia) XII, 2 (1992-94), pp. 7-32.

Rojo Guerra, M.A.; Jimeno Martínez, A.; Fernández Moreno, J.J. (1992): "El fenómeno megalítico en la provincia de Soria". Actas del $2^{2}$ Symposium de Arqueología Soriana, vol. I, pp. 163-183. Colección Temas Sorianos, n² 20. Excma. Diputación Provincial de Soria.

Rojo Guerra, M.A.; Negredo Garcia, M.J.; Sanz Aragones, A. (1995): "El túmulo de "La Peña de la Abuela", Ambrona (Soria) y el poblamiento neolítico de su entorno". RICUS (Geografía e Historia) XIII, 2, pp. 7-39.

Zapatero Magdaleno, P. (1991): "Sobre las relaciones entre Neolítico Interior y Megalitismo. Notas sobre el túmulo de La Velilla en Osorno (Palencia)", BSAA, LVII, pp. 53-61.

ZveleBiL, M. (1986): "Mesolithic prelude and neolithic revolution", En M. Zvelebil (ed): Hunters in transition. Mesolithic societies of temperate Eurasia and their transation to farming. Cambridge University Press, pp. 5-15. 